\title{
What is Qualitative in Research
}

\author{
Patrik Aspers ${ }^{1} \cdot$ Ugo Corte $^{2}$
}

Accepted: 12 October 2021/Published online: 28 October 2021

(c) The Author(s) 2021

\begin{abstract}
In this text we respond and elaborate on the four comments addressing our original article. In that piece we define qualitative research as an "iterative process in which improved understanding to the scientific community is achieved by making new significant distinctions resulting from getting closer to the phenomenon studied." In light of the comments, we identify three positions in relation to our contribution: (1) to not define qualitative research; (2) to work with one definition for each study or approach of "qualitative research" which is predominantly left implicit; (3) to systematically define qualitative research. This article elaborates on these positions and argues that a definition is a point of departure for researchers, including those reflecting on, or researching, the fields of qualitative and quantitative research. The proposed definition can be used both as a standard of evaluation as well as a catalyst for discussions on how to evaluate and innovate different styles of work.
\end{abstract}

Keywords Qualitative research · Methods · Epistemology · Standards of valuation · Research styles

The editors of Qualitative Sociology have given us the opportunity not only to receive comments by a group of particularly qualified scholars who engage with our text in a constructive fashion, but also to reply, and thereby to clarify our position. We have read the four essays that comment on our article What is qualitative in qualitative research (Aspers and Corte 2019) with great interest. Japonica BrownSaracino, Paul Lichterman, Jennifer Reich, and Mario Luis Small agree that what we do is new. We are grateful for the engagement that the four commenters show with our text.

Patrik Aspers

Patrik.aspers@unisg.ch

Ugo Corte

ugo.corte@uis.no

1 University of St., Gallen, St. Gallen, Switzerland

2 University of Stavanger, Stavanger, Norway 
Our article is based on a standard approach: we pose a question drawing on our personal experiences and knowledge of the field, make systematic selections from existing literature, identify, collect and analyze data, read key texts closely, make interpretations, move between theory and evidence to connect them, and ultimately present a definition: "qualitative research as an iterative process in which improved understanding to the scientific community is achieved by making new significant distinctions resulting from getting closer to the phenomenon studied" (Aspers and Corte 2019, 139). We acknowledge that there are different qualitative characteristics of research, meaning that we do not merely operate with a binary code of qualitative versus non-qualitative research. Our definition is an attempt to make a new distinction that clarifies what is qualitative in qualitative research and which is useful to the scientific community. Consequently, our work is in line with the definition that we have proposed.

Given the interest that our contribution has already generated, it is reasonable to argue that the new distinction we put forth is also significant. As researchers we make claims about significance, but it is always the audience-other scientists-who decide whether the contribution is significant or not. Iteration means that one goes back and forth between theory and evidence, and improved understanding refers to the epistemic gains of a study. To achieve this improved understanding by pursuing qualitative research, it is necessary that one gets close to the empirical material. When these four components are combined, we speak of qualitative research.

The four commentators welcome our text, which does not imply that they agree with all of the arguments we advance. In what follows, we single out some of the most important critiques we received and provide a reply aiming to push the conversation about qualitative research forward.

\section{Why a Definition?}

We appreciate that all critics have engaged closely with our definition. One main point of convergence between them is that one should not try to define qualitative research. Small (Forthcoming) asks rhetorically: "Is producing a single definition a good idea?" He justifies his concern by pointing out that the term is used to describe both different practices (different kinds of studies) and three elements (types of data; data collection, and analysis). Similarly, both BrownSaracino (Forthcoming) and Lichterman, (Forthcoming) argue that not only there is no single entity called qualitative research - a view that we share, but instead, that definitions change over time. For Small, producing a single definition for a field as diverse as sociology, or the social sciences for that matter, is restrictive, a point which is also, albeit differently, shared by Brown-Saracino. Brown-Saracino asserts that our endeavor "might calcify boundaries, stifle innovation, and prevent recognition of areas of common ground across areas that many of us have long assumed to be disparate." Hence, one should not define what is qualitative, because definitions may harm development. Both Small and Brown-Saracino say that we are drawing boundaries between qualitative and quantitative approaches and overstate differences between them. Yet, part of our intent was the opposite: 
to build bridges between different approaches by arguing that the 'qualitative' feature of research pertains both quantitative and qualitative methodologies, which may use and even combine different methods.

In light of these comments we need to elaborate our argument. Moreover, it is important not to maintain hard lines that may lead to scientific tribalism. Nonetheless, the critique of our-or any other definition of qualitative research-typically implies that there is something "there," but that we have not captured it correctly with our definition. Thus, the critique that we should not define qualitative research comes with an implicit contradiction. If all agree that there is something called "qualitative research," even if it is only something that is not quantitative, this still presumes that there is something called "qualitative." Had we done research on any other topic it would probably have been requested by reviewers to define what we are talking about. The same criteria should apply also when we turn the researcher's gaze on to our own practice.

Moreover, it is doubtful that our commentators would claim that qualitative research can be "anything," as the more Dadaistic interpretation by Paul Feyerabend (1976) would have it. But without referring to the realist view of Karl Popper $(1963,232-3)$ and his ideas of verisimilitude (i.e., that we get close to the truth) we have tried to spell out what we see as an account of the phenomenology of "qualitative." We identify three positions in relation to the issue of definition of qualitative research:

1. We should not define qualitative research.

2. We can work with one definition for each study or approach of "qualitative research," which is predominantly left implicit.

3. We can try to systematically define qualitative research.

Obviously, we have embraced and practiced position 3 in reaction to the current state of the field which is largely dominated by position 2--namely that what is qualitative research is open to a large variety of "definitions." The critical points of our commentators explicitly or implicitly argue in favor of position 1 , or perhaps position 2. Our claim that a definition can help researchers sort good from less good research has triggered criticism. Below, we elaborate on this issue.

We maintain that a definition is a valid starting point useful for junior scholars to learn more about what is qualitative and what is quantitative, and for more advanced researchers it may feature as a point of departure to make improvements, for instance, in clarifying their epistemological positions and goals. But we could have done a better job in clarifying our position. Nonetheless, we contend that change and improvement at this late stage of development in social sciences is partially related to and dependent upon pushing against or building upon clear benchmarks, such as the definition that we have formulated. We acknowledge that "definitions might evolve or diversify over time," as Brown-Saracino suggests. Still, surely social scientists can keep two things in mind at the same time: an existing definition may be useful, but new research may change it. This becomes evident if one applies our definition to the definition itself: our definition 
is not immune to work that leads to new qualitative distinctions! Having said this, we are happy to see that all four comments profit from getting in close contact with the definition. This means that our definition and the article offer the reader an opportunity to think with (Fine and Corte 2022) or, as Small writes, "forces the reader to think." We believe that both in principle and in practice, we all agree that clarity and definitions are scientific virtues.

\section{What can a Definition Enable?}

While we agree with several points in Small's essay, we disagree on others. Our underlying assumption is that we can build on existing knowledge, albeit not in the way positivism envisioned it. It follows that work which is primarily descriptive, evocative, political, or generally aimed at social change may entail new knowledge, but it does not fit well within the frame within which we operate in this piece. The existence of different kinds of work, each of which relies on different standards of evaluation-which are often unclear and consequential, especially to graduate students and junior scholars (see Corte and Irwin 2017) - brings us to another point highlighted by both Small and Lichterman: can the definition be used to differentiate good from lesser good kinds of work?

Small argues that while our article promises to develop a standard of evaluation, it fails to do so. We agree: our definition does not specify the exact criteria of what is good and what is poor research. Our definition demarcates qualitative research from non-qualitative by spelling out the qualitative elements of research, which advances a criterion of evaluation. In addition, there is definitely research that meets the characteristics of being qualitative, but that is uninteresting, irrelevant, or essentially useless (see Alvesson et al. 2017 on "gap spotting," for instance). What is good or not good research is to be decided in an ongoing scientific discussion led by those who actively contribute to the development of a field. A definition, nonetheless, can serve as a point of reference to evaluate scholarly work, and it can also serve as a guideline to demarcate what is qualitative from what it is not.

\section{A Good Definition?}

Even if one accepts that there should be a definition of qualitative research, and thinks that such a definition could be useful, it does not follow that one must accept our definition. Small identifies what he sees a paradox in our text, namely that we both speak of qualitative research in general and of qualitative elements in different research activities. The term qualitative, as we note and as Small specifies, is used to describe different things: from small $n$ studies to studies of organizations, states, or other units conceptualized as case studies and analyzed quantitatively as well as qualitatively. We are grateful for this observation, which is correct. We failed to properly address this issue in the original text.

As we discuss in the article, the elements used in our definitions (distinctions, process, closeness, and improved understanding) are present in all kinds of research, 
even quantitative. Perhaps the title of our article should have been: "What is Qualitative in Research?" Our position is that only when all the elements of the definition are applied can one speak of qualitative research. Hence, the first order constructs (i.e., the constructs the actors in the field have made) (Aspers 2009) of, for example, "qualitative observations," may indeed refer to observations that make qualitative distinction in the Aristotelian sense on which we rely. Still, if these qualitative observations are commensurated with a ratio-scale (i.e., get reduced to numbers) this research can no longer be called "qualitative." It is for this reason that we say that, to refer to first order constructs, "quantitative" research processes entail "qualitative" elements. This research is, as it were, partially qualitative, but it is not, taken together, qualitative research. Brown-Saracino raises a similar point in relation to her own and others works that combine "qualitative" and "quantitative" research. We do not think that one is inherently better, yet we agree with the general idea that qualitative research is particularly useful in identifying research questions and formulating theories (distinctions) that, at a later point should, when possible, be tested quantitatively on larger samples (cf. Small 2005). It is our hope that, with our clarification above, it will be easier for researchers to understand what one is and what one is not doing. We also hope that our study will stimulate further dialogue and collaboration between researchers who primarily work within different traditions.

Small wonders if a researcher who tries to replicate a "qualitative" study (according to our definition) is doing qualitative research. The person is certainly doing research, and some elements are likely conducted in a qualitative fashion according to our definition, for example if the method of in-depth fieldwork is employed. But regardless of the method used, and regardless of whether the person finds new things, if the result is binary coded as either confirming or disconfirming existing research, qualitative research is not being conducted because no new distinction is offered. Imagine the same study being replicated for the $20^{\text {th }}$ time. Surely the researcher must use the same "qualitative" methods (to use the first order construct). It may even excite a large academic audience, but it would not count as qualitative research according to our definition. Our definition requires both that the research process has made use of all its elements, but it also requires the acceptance by the audience. Having said this, in practice, it is more likely that such a study would also report new distinctions that are acknowledged by an audience. If such a study is reviewed and published, these are additional indicators that the new distinctions are considered significant, at least to some extent: how much research space it opens up, and how much it helps other researchers continue the discussion by formulating their own questions and making their own claims (Collins 1998, 31), whether by agreeing with it by applying it, by refining it (Snow et al. 2003), or by disagreeing and identifying new ways forward. There are two key characteristics that make a contribution relevant: newness and usefulness (Csikszentmihalyi 1996), both of which are related to the established state of knowledge within a field. Relatedly, Small asks: "Is newness enough? What does a new distinction that does not improve understanding look like?" There are also other indicators that demarcate whether a contribution is significant and to what extent. Some of these indicators include the number of citations a piece of work generates, the reputation of the journal or press where the work is published, and how widely the contribution is used-for instance, 
across specializations within the same discipline, or across different fields (i.e., different ways of valuation and evaluation) (Aspers and Beckert 2011) of scientific output. In principle, if a contribution ends up being used in an area where it would have unlikely been used, then one may further argue for its significance.

As it is implicit in our work when we talk about distinctions, we refer to theory building, albeit appreciating different conceptualizations and uses of the term theory (Abend 2008) and ways to achieve it (e.g., Zerubavel 2020). Brown-Saracino writes that our project may hold "the unintended consequence of limiting exploratory research designs and methodological innovations." While we cannot predict the impact of our research, we are certainly in favor of experimentation and different styles of work. In line with David Snow, Calvin Morrill and Leon Anderson (2003, 184), we argue that many qualitative researchers start their projects being underprepared in theory and theory development, oftentimes with the goal of describing, and leaving alone the black box of theory, or postponing it to later phases of the project. Our definition, along with the work by those authors and others on theory development, can be one way to heighten the chances researchers can make distinctions and develop theory.

Lichterman argues that we are not giving enough weight to interpretation and that we should relate more strongly to the larger project of the Geistenwissenschaften. We agree that interpretation is a key element in qualitative research, and we draw on Hans-Georg Gadamer (1988) who refined the idea of the hermeneutic circle.

Another critique, raised by Reich (Forthcoming), is that positionality is a key element of qualitative research. That in working towards a definition, we have "overlooked much of the methodological writings and contributions of women, scholars of color, and queer scholars" that could have enriched our definition, especially regarding "getting closer to the phenomenon studied." Surely, the way we have searched for and included references means that we have 'excluded' the vast majority of research and researchers who do qualitative work. However, we have not included texts by some authors in our sample based on any specific characteristics or according to any specific position. This critique is valid only if Reich shows more explicitly what this inclusion would add to our definition.

Though we agree with much of what Reich says, for example about the role of bodies and reflexivity in ethnographic work, the idea of positionality as a normative notion is problematic. At least since Gadamer wrote in the early 1960s (1988), it is clear that there are no interpretations 'from nowhere.' Who one is cannot be bracketed in an interpretation of what has occurred. The scientific value of this more identity- and positionality-oriented research that accounts also of the positionality of the interpreter, is essentially already well acknowledged. Reflection is not just something that qualitative researcher do; it is a general aspect of research. Ethnographic researchers may need certain skills to get close and understand the phenomenon they study, yet they also need to maintain distance. As Fine and Hallett write: "The ethnographic stranger is uniquely positioned to be a broker in connecting the field with the academy, bringing the site into theory and, perhaps, permitting the academy to consider joint action with previously distant actors" (Fine and Hallett 2014, 195). Moreover, Brown-Saracino illustrates well what it means to get close, and we too see that ethnography, in various forms and ways, is useful as other qualitative 
activities. Though ethnographic research cannot be quantitative, qualitative work is broader than solely ethnographic research. Furthermore, reflexivity is not something that one has to do when doing qualitative research, but something one does as a researcher.

Reich's second point is more important. The claim is that if the standpoint-oriented argument is completely accepted, it will most likely violate what we see as the essence of research. We warned in our article that qualitative research may be treated as less scientific than quantitative within academia, but also in the general public, if too many in academia claim to be doing "qualitative research" while they are in fact telling stories, engaging in activism, or writing like journalists. Such approaches are extra problematic if only some people with certain characteristics are viewed as the only legitimate producers of certain types of knowledge. If these tendencies are fueled, it is not merely the definition of "qualitative" that is at stake, but what the great majority see as research in general. Science cannot reach "The Truth," but if one gives up the idea communal and universal nature of scientific knowledge production and even a pragmatic notion of truth, much of its value and rationale of science as an independent sphere in society is lost (Merton 1973; Weber 1985). Ralf Dahrendorf framed this form of publicness by writing that: "Science is always a concert, a contrapuntal chorus of the many who are engaged in it. Insofar as truth exists at all, it exists not as a possession of the individual scholar, but as the net result of scientific interchange" $(1968,242-3)$. The issue of knowledge is a serious matter, but it is also another debate which relates to social sciences being low consensus fields (Collins 1994; Fuchs 1992; Parker and Corte 2017, 276) in which the proliferation of journals and lack of agreement about common definitions, research methods, and interpretations of data contributes to knowledge fragmentation. To abandon the idea of community may also cause confusion, and piecemeal contributions while affording academics a means to communicate with a restricted in-group who speak their own small language and share their views among others of the same tribe, but without neither the risk nor possibility of gaining general public recognition. In contrast, we see knowledge as something public, that, ideal-typically, "can be seen and heard by everybody" (Arendt 1988, 50), reflecting a pragmatic consensual approach to knowledge, but with this argument we are way beyond the theme of our article.

Our concern with qualitative research was triggered by the external critique of what is qualitative research and current debates in social science. Our definition, which deliberately tries to avoid making the use of a specific method or technique the essence of qualitative, can be used as a point of reference. In all the replies by Brown-Saracino, Lichterman, Reich, and Small, several examples of practices that are in line with our definition are given. Thus, the definition can be used to understand the practice of research, but it would also allow researchers to deliberately deviate from it and develop it. We are happy to see that all commentators have used our definition to move further, and in this pragmatic way the definition has already proved its value.

New research should be devoted to delineating standards and measures of evaluation for different kinds of work such as the those we have identified above: 
theoretical, descriptive, evocative, political, or aimed at social change (see Brady and Collier 2004; Ragin et al. 2004; Van Maanen 2011). And those standards could respectively be based upon scientific or stylistic advancement and social and societal impact. ${ }^{1}$ Different work should be evaluated in relation to their respective canons, goals, and audiences, and there is certainly much to gain from learning from other perspectives. Relatedly, being fully aware of the research logics of both qualitative and quantitative traditions (Small 2005) is also an advantage for improving both of them and to spur further collaboration. Bringing further clarity on these points will ultimately improve different traditions, foster creativity potentially leading to innovative projects, and be useful both to younger researchers and established scholars.

Acknowledgements The authors are grateful for comments by Gary Alan Fine, Jukka Gronow, and John Parker.

Funding Open access funding provided by University of St. Gallen. The research reported here is funded by University of St. Gallen, Switzerland and University of Stavanger, Norway.

Open Access This article is licensed under a Creative Commons Attribution 4.0 International License, which permits use, sharing, adaptation, distribution and reproduction in any medium or format, as long as you give appropriate credit to the original author(s) and the source, provide a link to the Creative Commons licence, and indicate if changes were made. The images or other third party material in this article are included in the article's Creative Commons licence, unless indicated otherwise in a credit line to the material. If material is not included in the article's Creative Commons licence and your intended use is not permitted by statutory regulation or exceeds the permitted use, you will need to obtain permission directly from the copyright holder. To view a copy of this licence, visit http://creativecommons.org/licen ses/by/4.0/.

\section{References}

Abend, Gabriel. 2008. The meaning of "theory". Sociological Theory 26 (2): 173-199.

Alvesson, Mats, Yannis Gabriel, and Roland Paulsen. 2017. Return to meaning. Oxford: Oxford University Press.

Arendt, Hannah. 1988. The human condition. Chicago: Chicago University Press.

Aspers, Patrik. 2009. Empirical phenomenology: A qualitative research approach (the Cologne Seminars). Indo-Pacific Journal of Phenomenology 9 (2): 1-12.

Aspers, Patrik, and Ugo Corte. 2019. What is qualitative in qualitative research. Qualitative Sociology 42 (2): $139-160$.

Aspers, Patrik, and Jens Beckert. 2011. Introduction. In The worth of goods, eds. Jens Beckert and Patrik Aspers, 3-38. Oxford: Oxford University Press.

\footnotetext{
1 The last two terms refer to whether the impacts are more micro as related to agency, or macro, as related to structural changes. An example of the latter kind is Matthew Desmond's Eviction (2016) having substantial societal impact on public policy discussions, raising and researching a broader range of housing issues in the US. A case of the former is Arlie Hochchild's studies on emotional labor of women in the workplace (1983) and her more recent book on the alienation of white, working-class Americans (2016).
} 
Brady, Henry E., and David Collier, eds. 2004. Rethinking social inquiry: Diverse tools, shared standards. Berkeley: Rowman \& Littlefield and Berkeley Public Policy Press.

Brown-Saracino, Japonica. Forthcoming. Unsettling definitions of qualitative research. Qualitative Sociology.

Collins, Randall. 1994. Why the social sciences won't become high-consensus, rapid-discovery science. Sociological Forum 9 (2): 155-177.

Collins, Randall. 1998. The sociology of philosophies: A global theory of intellectual change. Cambridge, MA: Harvard University Press.

Corte, Ugo, and Katherine Irwin. 2017. The form and flow of teaching ethnographic knowledge: Handson approaches for learning epistemology. Teaching Sociology 45 (3): 209-219.

Csikszentmihalyi, Mihaly. 1996. Creativity: Flow and the psychology of discovery and iinvention. New York: Harper/Collins.

Dahrendorf, Ralf. 1968. Essays in the theory of society. Stanford: Stanford University Press.

Desmond, Matthew. 2016. Evicted: Poverty and profit in the American City. New York: Crown Publishers.

Feyerabend, Paul. 1976. Against method. London: NLB.

Fine, Gary Alan and Ugo Corte. 2022. Dark fun: The cruelties of hedonic communities. Sociological Forum 37 (1).

Fine, Gary Alan, and Tim Hallett. 2014. Stranger and stranger: Creating theory through thnographic Distance and Authority. Journal of Organizational Ethnography 3 (2): 188-203.

Fuchs, Stephan. 1992. The professional quest for truth. New York: SUNY Press.

Gadamer, Hans Georg. 1988. On the circle of understanding. In Hermenutics versus science, three German views: Wolfgang Stegmüller, Hans Georg Gadamer, Ernst Konrad Specht, eds. John Connolly and Thomas Keutner, 68-78. Notre Dame: University of Notre Dame.

Hochschild, Arlie. 1983. The managed heart: Comercialization of human feeling. Berkeley: University of California Press.

Hochschild, Arlie. 2016. Strangers in their own land: Anger and mourning on the American right. New York: The New Press.

Lichterman, Paul. Forthcoming. "Qualitative research" is a moving target. Qualitative Sociology.

Merton, Robert K. 1973. Structure of science. In The sociology of science: Theoretical and empirical investigations, ed. Robert K. Merton, 267-278. Chicago: University of Chicago Press.

Parker, John N., and Ugo Corte. 2017. Placing collaborative circles in strategic action fields: Explaining differences between highly creative groups. Sociological Theory 35 (4): 261-287.

Popper, Karl. 1963. Conjectures and refutations: The growth of scientific knowledge. London: Routledge and Kegan Paul.

Ragin, Charles, Joane Nagel, and Patricia White. 2004. Workshop on scientific foundations of qualitative research. National Research Foundation. https:/www.nsf.gov/pubs/2004/nsf04219/nsf04219.pdf. Acessed 29 September 2021.

Reich, Jennifer. Forthcoming. Power, positionality, and the ethic of care in qualitative research. Qualitative Sociology.

Small, Mario Luis 2005. Lost in translation: How not to make qualitative research more scientific. https:// citeseerx.ist.psu.edu/viewdoc/download?doi=10.1.1.497.4161\&rep=rep1\&type=pdf. Accessed 23 September 2021.

Small, Mario Luis. Forthcoming. What is "qualitative" in qualitative research? Why the answer does not matter but the question is important. Qualitative Sociology.

Snow, David A., Calvin Morrill, and Leon Anderson. 2003. Elaborating analytic ethnography: Linking fieldwork and theory. Ethnography 4 (2): 181-200.

Van Maanen, John. 2011. Tales of the field: On writing ethnography. Chicago: Chicago University Press.

Weber, Max. 1985. Gesammelte aufsätze zur wissenschaftslehre. Edited by J. Winckelmann. Tübingen: J.C.B.Mohr.

Zerubavel, Eviatar. 2020. Generally speaking: An invitation to concept-driven sociology. Oxford: Oxford University Press.

Publisher's Note Springer Nature remains neutral with regard to jurisdictional claims in published maps and institutional affiliations. 
Patrik Aspers is chair of Sociology at the University of St. Gallen, Switzerland. He has published several books and numerous articles in the fields of sociological theory, economic sociology, phenomenology, and qualitative research. He has conducted ethnographic fieldwork in several countries. Aspers is currently writing a book called Uncertainty Reduction and is doing research on this topic as well as on marketplaces.

Ugo Corte PhD from Uppsala University in 2012, is Associate Professor of Sociology at the University of Stavanger, Norway. His work on the sociology of creativity, microsociology, and qualitative methods has been published in journals like Sociological Theory, Social Psychology Quarterly, and Teaching Sociology. His ethnographic book Dangerous Fun: The Social Lives of Big Wave Surfers will be published by The University of Chicago Press in May 2022. 